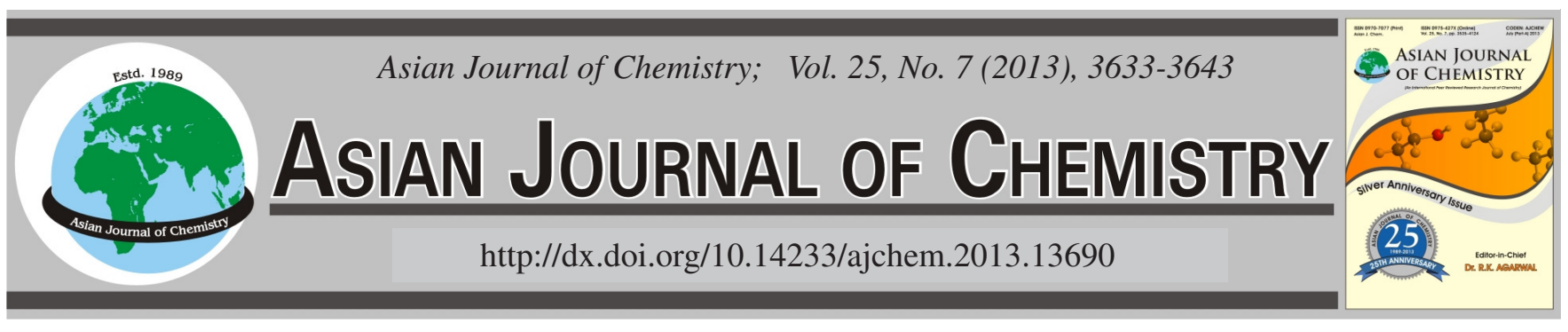

\title{
DFT Study of the Effect of Different Metals on Structures and Electronic Spectra of Some Organic-Metal Compounds as Sensitizing Dyes
}

\author{
Guodong Tang ${ }^{1,2, *}$, Rongqing $\mathrm{Li}^{2}$, Shanshan $\mathrm{Kou}^{2,3}, \mathrm{Hu}_{\mathrm{Zhou}}^{2,4}, \mathrm{Yu}_{\mathrm{Zhang}}{ }^{2}$, Xuehai Ju ${ }^{1}$ and Changmei Wei ${ }^{2}$
}

\begin{abstract}
${ }^{1}$ School of Chemical Engineering, Nanjing University of Science and Technology, Nanjing 210094, P.R. China
${ }^{2}$ Jiangsu Key Laboratory for Chemistry of Low-Dimensional Materials, School of Chemistry and Chemical Engineering, Huaiyin Normal University, Huai'an 223300, Jiangsu Province, P.R. China

${ }^{3}$ School of Chemistry \& Chemical Engineering, Ningxia University, Yinchuan 750021, P.R. China

${ }^{4}$ College of Chemistry and Chemical Engineering, Nanjing University of Technology, Nanjing 210009, P.R. China
\end{abstract}

*Corresponding author: Fax: +86 517 83525320; Tel: +86 517 83525318; E-mail: hysytanggd@ hotmail.com

(Received: 7 March 2012;

Accepted: 7 January 2013)

AJC-12665

Ruthenium polypyridine-derivative complexes are used in dye-sensitized solar cell (DSSC) as a light to current conversion sensitizer. In
order to lower cost of the dye-sensitized solar cell, the normal transition metals were used to replace the noble metal ruthenium and some
compounds $\left[\mathrm{ML}_{2}\right]\left(\mathrm{M}=\mathrm{Ru}, \mathrm{Ni}, \mathrm{Mn}, \mathrm{Cu} ; \mathrm{L}=5\right.$ '-methyl-2, 2'-bipyridine-6-carboxylato, $\mathbf{I}=\mathrm{RuL}_{2}, \mathrm{II}=\mathrm{NiL}_{2}, \mathrm{III}=\mathrm{MnL}, \mathrm{IV}=\mathrm{CuL}_{2}$ ) were
selected as the replacement. The geometries, electronic structures and optical absorption spectra of these compounds have been studied by
using density functional theory (DFT) calculation at the B3P86/LANL2DZ level of theory. The maximum absorptions of complexes are
found to be at 646 and $979 \mathrm{~nm}$ for compound III and $617 \mathrm{~nm}$ for compound IV. The $\lambda_{\text {max }}$ band in complexes III and IV have a large red-
shift when compared to the standard compound I. This means that the panchromatic response of compounds III and IV renders it as a
suitable sensitizer for solar energy conversion applications.

Key Words: DFT, Different metals, Organic-metal compounds, Sensitizing dyes.

\section{INTRODUCTION}

The new types of dye sensitized solar cells (DSSCs) have attracted a considerable amount of interest since Grätzel and co-workers ${ }^{1-4}$ reported that the photoelectricity conversion efficiency was obtained to be more than $7.1 \%$ and they offer the possibility of low-cost conversion of photovoltaic energy. To increase the photoconversion efficiency, different approaches are still being studied to improve the photoelectricity conversion efficiency of the dye-sensitized solar cell, such as the nature of semiconductors $\left(\mathrm{TiO}_{2}, \mathrm{SnO}_{2}, \mathrm{ZnO}, \mathrm{NiO} \text {, etc. }\right)^{5-8}$, the morpho$\operatorname{logy}$ of semiconductors $\left(\mathrm{TiO}_{2}, \mathrm{ZnO} \text { etc. }\right)^{9-11}$ and the forms of electrolytes ${ }^{12,13}$. In the cells, the sensitizer is one of the key components, harvesting the solar radiation and converting it to electric current.

It has been found that many organic-metal compounds possess promising high conversion efficiency since these kinds of organic-metal compounds were found to combine the advantages of molecular tunability with the material properties of wide band-gap semiconductors, such as stability toward corrosion, charge transport and mechanical resilience. Until now, many efforts have been done on the syntheses of new ruthenium complexes and determinations of their electronic spectra ${ }^{14-20}$ and state-of-the-art dye-sensitized solar cells based on ruthenium(II)-polypyridyl complexes as the active material have an overall power conversion efficiency $(\eta)$ approaching $11 \%$ under standard (Global Air Mass 1.5) illumination ${ }^{21-24}$. The ruthenium polypyridine and polypyridine-derivative complexes have been widely investigated for many years both experimentally and theoretically. Komatsuzaki and co-workers ${ }^{25}$ synthesized a series of ruthenium (II)-polypyridyl complexes as a sensitizer for dye-sensitized solar cell and characterized their photophysical and photochemical properties; the complexes showed broad electronic absorption bands in the nearIR region. $\mathrm{Xu}$ and co-workers ${ }^{26}$ reported the behaviours of $\mathrm{RuL}_{2}$ (L = 5'-methyl-2, 2'-bipyridine-6-carboxyl) in the gas phase and DMF solution by the TD-DFT method. Their calculation results indicate that the two maximum absorption peaks are blue-shifted in DMF solution in comparison with those in the gas phase. Nazeeruddin ${ }^{27}$ and co-workers reported a ruthenium complex trans-[Ru(L')(NCS) $\left.)_{2}\right]$, where $\mathrm{L}^{\prime}=4,4{ }^{\prime \prime}-$ di-tert-butyl-4', 4"-bis(carboxylic acid)-2, 2':6', 2":6", 2"' quaterpyridine (N886) and the complex was characterized by spectroscopic and electrochemical methods. The electronic 
spectrum of the N886 complex was also calculated by TDDFT method. The result showed its absorption bands as mixed $\mathrm{Ru} / \mathrm{SCN}$-to-quarterpyridine charge-transfer transitions, which extend from the near-IR to the UV regions. This suggests that it can act as a suitable sensitizer for solar energy conversion applications. These studies put the attention mainly on the effect of the different ligands on the dye-sensitized solar cells properties. However, ruthenium is a noble metal and it may be a bottleneck for the development of the low-cost dyesensitized solar cells. At present, little attentions have been paid to the normal transition metals and their effect on the dye-sensitized solar cells.

In order to reduce the cost of the dye-sensitized solar cells, we wish to use the normal transition metals to replace the noble metal. We selected a reported ruthenium polypyridine-derivative complex ${ }^{26,28}$ as an object of reference and the different transition metals were used to replace the ruthenium. In order to understand the relationship between the metals and the dyesensitized solar cells properties, the DFT methods were used to optimize the structures of those organic metals without any constrains in bond lengths, bond angles and dihedral angles and then calculated the electronic spectra of those optimized structures. The results would be helpful in the simulation, screening and design of new organic metal complexes as new dye-sensitized solar cells sensitizers.

\section{COMPUTATIONAL METHOD}

Due to the high accuracy, DFT has been proved to be more useful in calculating molecular properties of the organometallic compounds than the traditional ab initio electronic structure methods ${ }^{29,30}$. Some reports indicated that the ruthenium polypyridine-derivative complexes are efficient photosensitizers because of their broad range of visible light absorption and relatively long lived excited states, with energies almost matching those of $\mathrm{TiO}_{2}$ conduction band states ${ }^{31-34}$.

The geometries of these complexes were optimized using the DFT (B3LYP and B3P86) methods and the LANL2DZ or LANL2MB basis set ${ }^{35-40}$. The UV-visible spectra of these complexes were calculated with the same method. Geometry optimization is one of the most important steps in the theoretical calculations. This procedure proceeds in two steps. Firstly the geometry was constructed by $\mathrm{MM}+$ molecular dynamics in Hyper-Chem. 7.0 Package ${ }^{41}$ and then optimized by the DFT methods at B3LYP or B3P86 level with LanL2DZ or LANL2MB basis set using Gaussian 03W program package. The maximum values of the converged criterion are default. All geometries converged perfectly. The HOMO-LUMO gap was computed at the same theoretical level as that used in the geometry optimization. Meanwhile, the time-dependent density functional theory (TD-DFT) was employed to describe the electron absorption spectra of all organic metals.

\section{RESULTS AND DISCUSSION}

Structures: Any comparison between experimental and calculated data should require a precise knowledge of the molecular structure of the complexes. However, only a few crystal structures of these organic-metal complexes have been reported to date. We selected these reported crystal structure as comparison.
The fully optimized geometries of $\left[\mathrm{ML}_{2}\right](\mathrm{M}=\mathrm{Ru}, \mathrm{Ni}$, $\mathrm{Mn}, \mathrm{Cu} ; \mathrm{L}=5$ '-methyl-2, 2'-bipyridine-6-carboxylato) are shown in Fig. 1. The selected bond lengths and bond angles are given in Table-1, along with the available experimental $\operatorname{data}^{28}$.
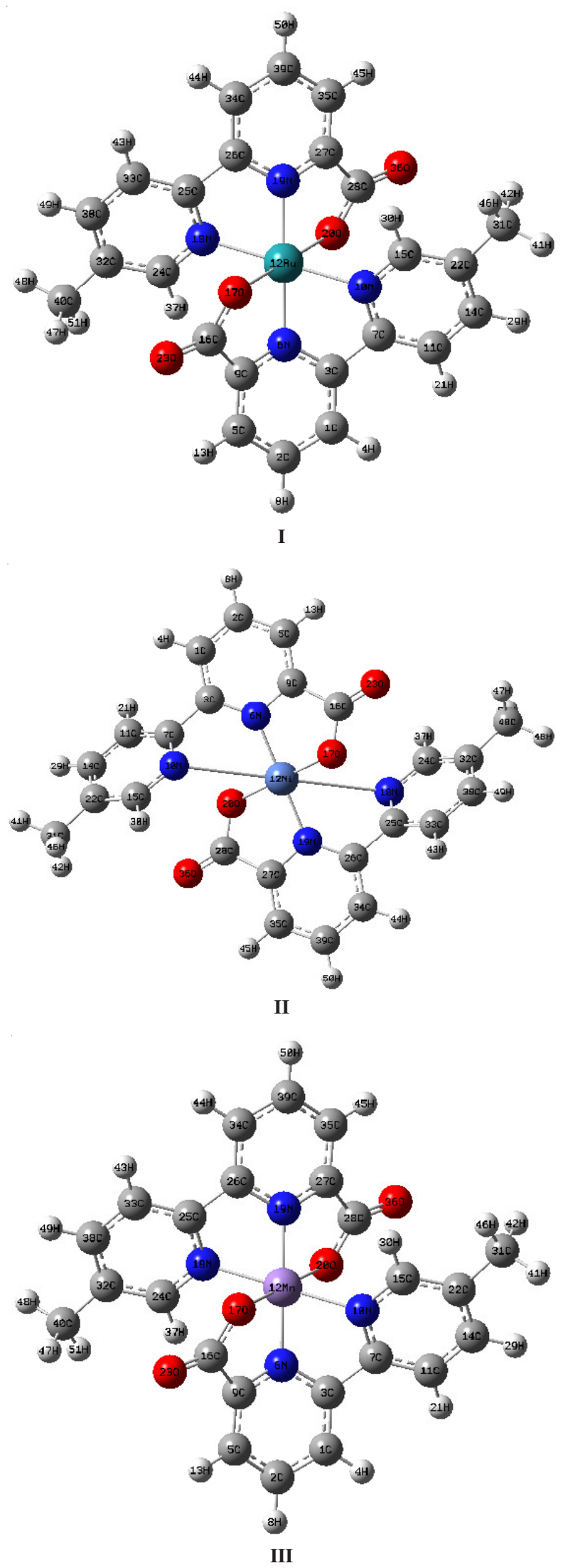


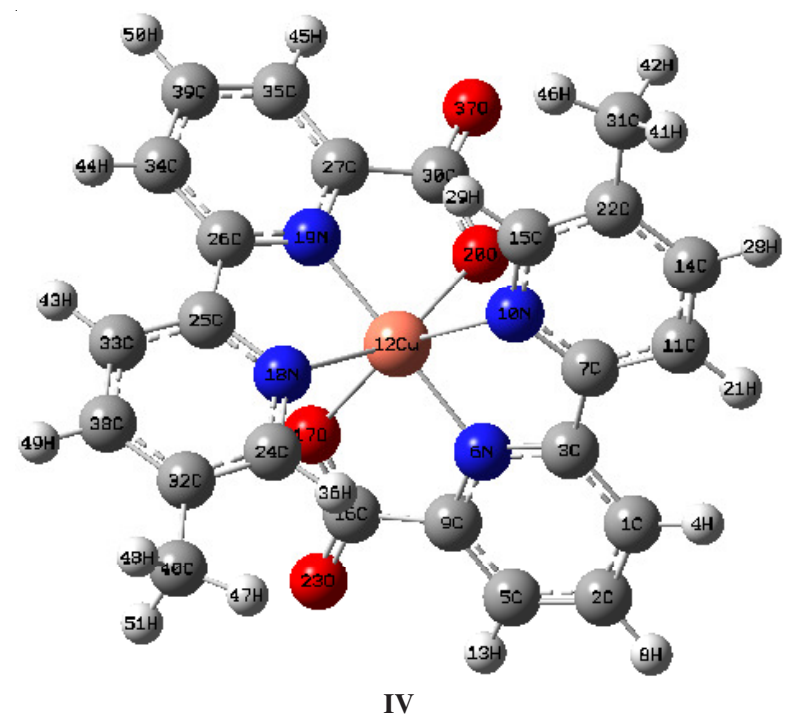

Fig. 1. Optimized geometries of $\mathrm{ML}_{2}$ complex. $(\mathrm{M}=\mathrm{Ru}, \mathrm{Ni}, \mathrm{Mn}, \mathrm{Cu}, \mathrm{L}=$ 5'-methyl-2, 2'-bipyridine-6-carboxylato), I $=\mathrm{RuL}_{2}, \mathbf{I I}=\mathrm{NiL}_{2}, \mathbf{I I I}$ $\left.=\mathrm{MnL}_{2}, \mathbf{I V}=\mathrm{CuL}_{2}\right)$

In order to evaluate the method exactness, we selected the reported structure ${ }^{28}$ for comparison. The relative errors for different methods (B3LYP/LANL2DZ, B3LYP/LANL2MB, B3P86/ LANL2DZ and B3P86/ LANL2MB) were in the range of $2.3-5.3,1.6-4.3,0.9-3.5$ and $1.7-3.0 \%$ for bond lengths and 4.8-7.0, 4.4-6.4, 4.6-6.6 and 4.2-6.1\% for bond angles, respectively. These geometric parameters are close to the experimental values, suggesting that these methods were appropriate for these types of compounds. Since the exact crystal structures of the other title compounds are not available till now, the optimized structures can only be compared with other similar systems for which the crystal structures have been reported $^{42-46}$. The $\mathrm{Cu}-\mathrm{N}$ bond length ranges in the literature are 1.952-2.006 $\AA^{42,43}$, while the calculated values with different methods (B3LYP/LANL2DZ, B3LYP/LANL2MB, B3P86/ LANL2DZ and B3P86/LANL2MB) are 1.981-2.361, 2.094$2.354,1.960-2.313,2.037-2.426 \AA$, respectively. The Mn-N bond length ranges in the literature are 2.252-2.282 $\AA^{44,45}$, while the calculated values with different methods (B3LYP/ LANL2DZ, B3LYP/LANL2MB, B3P86/LANL2DZ and B3P86/LANL2MB) are 1.948-2.131, 1.914-2.063, 1.9152.066, 1.892-2.031 $\AA$, respectively. The Ni-N bond length ranges are 2.064-2.084 $\AA^{46}$, while the calculated values with different methods (B3LYP/LANL2DZ, B3LYP/LANL2MB, B3P86/LANL2DZ and B3P86/LANL2MB) are 1.948, 1.934, $1.921,1.911 \AA$, respectively. The $\mathrm{Cu}-\mathrm{O}$ bond length ranges are 1.935-1.944 $\AA^{42,43}$, while the calculated values with different methods (B3LYP/LANL2DZ, B3LYP/LANL2MB, B3P86/ LANL2DZ and B3P86/LANL2MB) are 2.106-2.107, 2.012$2.069,2.099-2.099,2.125-2.125 \AA$, respectively. The Mn-O bond length ranges are 2.104-2.104 $\AA^{44,45}$, while the calculated values with different methods (B3LYP/LANL2DZ, B3LYP/ LANL2MB, B3P86/LANL2DZ and B3P86/ LANL2MB) are $2.059,1.891,2.022,1.878 \AA$, respectively. The Ni-O bond length ranges are $2.055 \AA^{46}$, while the calculated values with different methods (B3LYP/LANL2DZ, B3LYP/LANL2MB, B3P86/LANL2DZ and B3P86/ LANL2MB) are 1.870, 1.829, $1.856,1.820 \AA$, respectively. From the theoretical values we can find that all the geometric parameters are close to the experimental values except a $\mathrm{Ni}-\mathrm{N}$ bond length and the distances between the $\mathrm{M}-\mathrm{N}(\mathrm{O})(\mathrm{M}=\mathrm{Ru}, \mathrm{Cu}, \mathrm{Mn}, \mathrm{Ni})$ atoms are slightly smaller than that sum of the $\mathrm{M}$ atom and $\mathrm{N}(\mathrm{O})$ atom radius. This means that there is a bond between the $\mathrm{M}$ atom and the nearest $\mathrm{N}(\mathrm{O})$ atom. These geometric parameters are close to the experimental values although the errors of the B3LYP/LANL2MB method were larger than those obtained from the other methods; the errors are in acceptable range. The other $\mathrm{O}$ atom from the carboxyl group can not connect the $\mathrm{M}$ atom and this may be as a suitable sensitizer for solar energy conversion applications based on the semiconductor $\left(\mathrm{TiO}_{2}, \mathrm{SnO}_{2}, \mathrm{ZnO}, \mathrm{NiO}\right.$, etc.) mesoporous electrodes. The same methods were used to calculate the IR spectra of these compounds. The outcome shows that the structures of these compounds are stable as there is not any imaginary vibration model. The other properties were calculated base on these structures.

Electronic structure: Results for the electronic structure of these complexes were schematized in the molecular orbital energy diagram of Fig. 2. The local densities of states of compounds were listed in Table-2. The isodensity plots of selected frontier orbital's for $\mathrm{M}(\mathrm{II}) \mathrm{L}_{2}(\mathrm{M}=\mathrm{Ru}, \mathrm{Ni}, \mathrm{Mn}, \mathrm{Cu})$ were shown in Fig. 3.
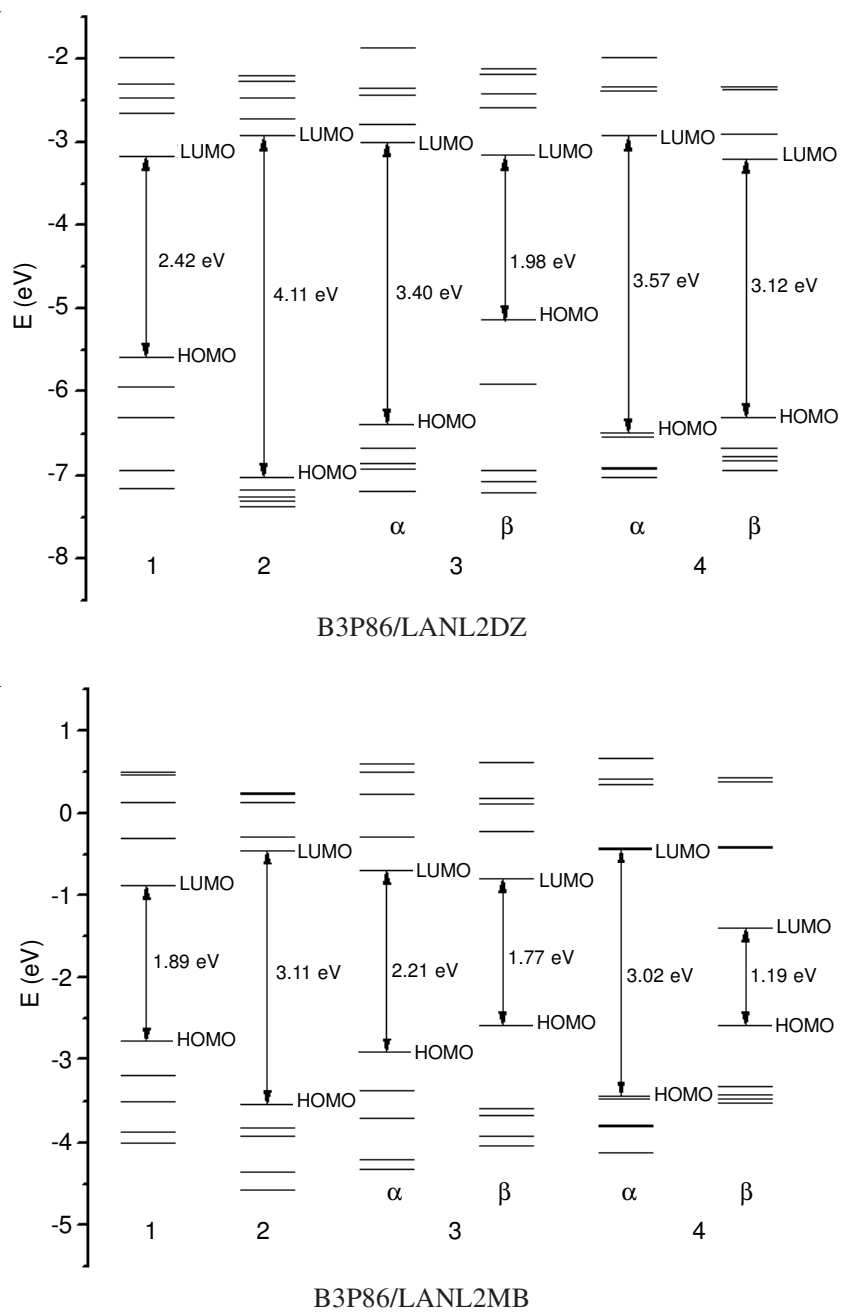

1. $\mathrm{Ru}(\mathrm{II}) \mathrm{L}_{2}, 2$. $\mathrm{Ni}(\mathrm{II}) \mathrm{L}_{2}, 3 . \mathrm{Mn}(\mathrm{II}) \mathrm{L}_{2}, 4 . \mathrm{Cu}(\mathrm{II}) \mathrm{L}_{2}$

Fig. 2. Energy levels (eV) of the complexes base on the B3P86/LANL2DZ and the B3P86/LANL2MB 
TABLE-1

SELECT BOND LENGTH $(\AA)$ AND BOND ANGLES $\left(^{\circ}\right)$ FOR ALL COMPOUNDS

\begin{tabular}{|c|c|c|c|c|c|c|}
\hline \multirow{2}{*}{ Compounds } & \multirow{2}{*}{ Parameters } & \multicolumn{2}{|c|}{ B3LYP } & \multicolumn{2}{|c|}{ B3P86 } & \multirow{2}{*}{ Exp. $^{28}$} \\
\hline & & Lanl2dz & Lanl2mb & Lanl2dz & Lanl2mb & \\
\hline \multirow{11}{*}{$\mathbf{I}$} & Ru12-N6 & 2.033 & 2.030 & 2.009 & 2.010 & 1.975 \\
\hline & Ru12-N10 & 2.140 & 2.119 & 2.104 & 2.093 & 2.042 \\
\hline & Ru12-N18 & 2.140 & 2.119 & 2.103 & 2.093 & 2.032 \\
\hline & Ru12-N19 & 2.033 & 2.030 & 2.009 & 2.010 & 1.976 \\
\hline & Ru12-O17 & 2.175 & 2.091 & 2.146 & 2.076 & 2.126 \\
\hline & Ru12-O20 & 2.175 & 2.091 & 2.146 & 2.076 & 2.127 \\
\hline & N18-Ru12-N19 & 73.8 & 74.4 & 74.3 & 74.6 & 79.4 \\
\hline & N10-Ru12-N6 & 73.8 & 74.4 & 74.3 & 74.6 & 79.5 \\
\hline & N6-Ru12-N19 & 180.0 & 180.0 & 180.0 & 180.0 & 178.8 \\
\hline & N10-Ru12-N19 & 106.0 & 105.6 & 105.7 & 105.4 & 101.1 \\
\hline & N18-Ru12-N6 & 106.0 & 105.6 & 105.7 & 105.4 & 99.6 \\
\hline \multirow{9}{*}{ II } & Ni12-N6 & 1.948 & 1.934 & 1.921 & 1.911 & $2.064^{46}$ \\
\hline & Ni12-N19 & 1.948 & 1.934 & 1.921 & 1.911 & 2.074 \\
\hline & Ni12-O17 & 1.870 & 1.829 & 1.856 & 1.820 & 2.055 \\
\hline & N18-Ni12-N19 & 58.9 & 61.6 & 59.6 & 61.8 & - \\
\hline & N18-Ni12-N10 & 179.9 & 180.0 & 180.0 & 180.0 & - \\
\hline & N10-Ni12-N6 & 59.0 & 61.6 & 59.6 & 61.8 & - \\
\hline & N6-Ni12-N19 & 180.0 & 180.0 & 180.0 & 180.0 & - \\
\hline & N10-Ni12-N19 & 121.0 & 118.4 & 120.4 & 118.2 & - \\
\hline & N18-Ni12-N6 & 121.1 & 118.4 & 120.4 & 118.2 & - \\
\hline \multirow{10}{*}{ III } & Mn12-N6 & 1.948 & 1.914 & 1.915 & 1.892 & $2.252^{44,45}$ \\
\hline & Mn12-N10 & 2.131 & 2.063 & 2.066 & 2.031 & 2.258 \\
\hline & Mn12-N18 & 2.131 & 2.063 & 2.066 & 2.031 & 2.282 \\
\hline & Mn12-N19 & 1.948 & 1.914 & 1.915 & 1.892 & 2.282 \\
\hline & Mn12-O17 & 2.059 & 1.891 & 2.022 & 1.878 & 2.104 \\
\hline & Mn12-O20 & 2.059 & 1.891 & 2.022 & 1.878 & 2.104 \\
\hline & N18-Mn12-N19 & 74.9 & 76.5 & 75.9 & 76.9 & 72.7 \\
\hline & N18-Mn12-N10 & 180.0 & 180.0 & 180.0 & 180.0 & 162.4 \\
\hline & N10-Mn12-N19 & 105.1 & 103.4 & 104.1 & 103.1 & 98.8 \\
\hline & N18-Mn12-N6 & 105.1 & 103.4 & 104.1 & 103.1 & 94.3 \\
\hline \multirow{14}{*}{ IV } & Cu12-N6 & 1.981 & 2.222 & 1.960 & 2.037 & $1.952^{42,43}$ \\
\hline & Cu12-N18 & 2.361 & 2.325 & 2.313 & 2.426 & 1.999 \\
\hline & Cu12-N19 & 1.981 & 2.094 & 1.960 & 2.037 & 2.006 \\
\hline & Cu12-O17 & 2.107 & 2.012 & 2.099 & 2.125 & 1.9440 \\
\hline & $\mathrm{Cu} 12-\mathrm{O} 20$ & 2.106 & 2.069 & 2.099 & 2.125 & 2.305 \\
\hline & O17-Cu12-N6 & 80.5 & 79.1 & 80.6 & 79.0 & 91.0 \\
\hline & O18-Cu12-N6 & 110.3 & 110.3 & 110.1 & 116.0 & 165.4 \\
\hline & N6-Cu12-N19 & 172.4 & 155.3 & 171.9 & 167.5 & 166.7 \\
\hline & N6-Cu12-N20 & 95.6 & 95.6 & 95.0 & 94.4 & 93.0 \\
\hline & O17-Cu12-N18 & 81.0 & 98.7 & 80.8 & 83.4 & 85.0 \\
\hline & O17-Cu12-N19 & 95.1 & 125.2 & 95.0 & 94.4 & 91.3 \\
\hline & N18-Cu12-N19 & 74.9 & 73.5 & 75.7 & 73.2 & 81.1 \\
\hline & N18-Cu12-N20 & 151.8 & 153.1 & 152.9 & 146.9 & - \\
\hline & N19-Cu12-N20 & 80.5 & 79.9 & 80.6 & 79.0 & 84.0 \\
\hline
\end{tabular}

In Fig. 2, based on the B3P86/LANL2DZ and B3P86/ LANL2MB methods, we can see that the DEH-L values of compound I are 2.42 and $1.89 \mathrm{eV}$, respectively. The DEH-L values of compound II are 3.11 and $4.11 \mathrm{eV}$, which are larger than those of compound $\mathbf{I}$. This means that compound $\mathbf{I I}$ is not suitable as a sensitizer for solar energy conversion applications. For compounds III and IV, there are more electrons, thus the forms of electron transition are complex. The $\Delta \mathrm{E}_{\mathrm{H}-\mathrm{L}}$ values of compound III are 3.40/2.21 for $\alpha$ electron, 1.98/ 1.77 for $\beta$ electron and the $\Delta \mathrm{E}_{\mathrm{H}-\mathrm{L}}$ values of compound $\mathbf{I V}$ are $3.57 / 3.02$ for $\alpha$ electron, 3.12/1.19 for $\beta$ electron, respectively. These values are close to those of compound I, meaning that compounds III and IV may be used as sensitizers for solar energy conversion applications.

As shown in Table-2 and Fig. 3, for compound $\mathbf{I} \mathrm{Ru}(\mathrm{II}) \mathrm{L}_{2}$, the HOMO (133), HOMO-1, HOMO-2 are a set of quasidegenerated orbital's. Their largest orbital contributions derive from the metal atom (raging from 76-90\%) mixed with fewer characters of bipyridine rings and carboxylic groups (raging from 2-8 \%). The HOMO-3 and HOMO-4 are mainly on the carboxylic groups (raging from 38-46 \%). The five lowest LUMOs (134, 135, 136, 137 and 138) are almost entirely localized on the bipyridine rings (raging from 43-49\%), with only 1-7 \% contribution from metal orbital. The tendencies 


\begin{tabular}{|c|c|c|c|c|c|c|c|}
\hline \multicolumn{8}{|c|}{$\begin{array}{c}\text { TABLE-2 } \\
\text { ENERGIES AND PERCENTAGE COMPOSITION OF THE LOWEST UNOCCUPIED AND HIGHEST OCCUPIED } \\
\text { ORBITALS OF THE COMPLEX IN TERMS OF Ru, BIPYRIDINE RINGS AND CARBOXYLIC FRAGMENTS }\end{array}$} \\
\hline \multirow{2}{*}{ MO } & \multirow{2}{*}{ occ } & \multirow{2}{*}{$\mathrm{E}(\mathrm{eV})$} & \multirow{2}{*}{$\mathbf{I}$} & \multicolumn{2}{|c|}{ Bipyridine rings } & \multicolumn{2}{|c|}{ Carboxylic groups } \\
\hline & & & & Ring 1a & Ring $2 \mathrm{~b}$ & Group 1c & Group 2d \\
\hline 129 & 2 & -5.75 & 18 & 3 & 3 & 38 & 38 \\
\hline 130 & 2 & -5.41 & 2 & 2 & 3 & 46 & 46 \\
\hline 131 & 2 & -4.74 & 90 & 2 & 2 & 3 & 3 \\
\hline 132 & 2 & -4.03 & 80 & 2 & 2 & 8 & 8 \\
\hline 133 & 2 & -3.46 & 76 & 8 & 8 & 3 & 3 \\
\hline 134 & 0 & 3.96 & 1 & 5 & 48 & 1 & 1 \\
\hline 135 & 0 & 4.53 & 7 & 46 & 46 & 0 & 0 \\
\hline 136 & 0 & 5.34 & 1 & 48 & 45 & 4 & 4 \\
\hline 137 & 0 & 5.68 & 5 & 43 & 35 & 5 & 5 \\
\hline 138 & 0 & 5.80 & 1 & 49 & 49 & 1 & 1 \\
\hline \multirow{2}{*}{ MO } & \multirow{2}{*}{ occ } & \multirow{2}{*}{$\mathrm{E}(\mathrm{eV})$} & \multirow{2}{*}{ II } & \multicolumn{2}{|c|}{ Bipyridine rings } & \multicolumn{2}{|c|}{ Carboxylic groups } \\
\hline & & & & Ring 1a & Ring $2 b$ & Group 1c & Group 2d \\
\hline 121 & 2 & -7.43 & 3 & 32 & 27 & 19 & 15 \\
\hline 122 & 2 & -7.06 & 2 & 37 & 37 & 11 & 10 \\
\hline 123 & 2 & -6.68 & 2 & 18 & 15 & 30 & 32 \\
\hline 124 & 2 & -6.11 & 7 & 1 & 1 & 46 & 45 \\
\hline 125 & 2 & -1.01 & 72 & 8 & 7 & 6 & 7 \\
\hline 126 & 0 & 4.20 & 16 & 29 & 45 & 5 & 5 \\
\hline 127 & 0 & 4.89 & 1 & 54 & 40 & 2 & 2 \\
\hline 128 & 0 & 5.44 & 0 & 0 & 90 & 0 & 9 \\
\hline 129 & 0 & 5.56 & 0 & 89 & 1 & 6 & 0 \\
\hline 130 & 0 & 6.72 & 4 & 63 & 31 & 1 & 1 \\
\hline \multirow{2}{*}{ MO } & \multirow{2}{*}{ occ } & $\mathrm{F}(\mathrm{eV})$ & UU/ $/$ ) & Bipy & ings & Carb & roups \\
\hline & & $E(e V)$ & $\mathbf{I I}(\alpha)$ & Ring 1a & Ring $2 b$ & Group 1c & Group 2d \\
\hline 120 & 2 & -7.16 & 1 & 11 & 12 & 36 & 39 \\
\hline 121 & 2 & -7.07 & 1 & 42 & 39 & 9 & 9 \\
\hline 122 & 2 & -6.84 & 0 & 45 & 48 & 3 & 2 \\
\hline 123 & 2 & -6.24 & 1 & 1 & 4 & 4 & 39 \\
\hline 124 & 2 & -6.24 & 1 & 11 & 9 & 32 & 48 \\
\hline 125 & 0 & 4.69 & 1 & 50 & 42 & 1 & 1 \\
\hline 126 & 0 & 4.76 & 1 & 36 & 55 & 0 & 0 \\
\hline 127 & 0 & 5.48 & 2 & 51 & 4 & 7 & 4 \\
\hline 128 & 0 & 5.50 & 1 & 36 & 51 & 4 & 7 \\
\hline 129 & 0 & 5.90 & 1 & 49 & 40 & 1 & 1 \\
\hline 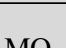 & (sce & $\mathrm{E}(\mathrm{V})$ & $\boldsymbol{\mu}(\boldsymbol{\beta})$ & Bipy & ings & Carb & roups \\
\hline MO & occ & $E(e v)$ & $\mathbf{I I}(\boldsymbol{\beta})$ & Ring 1a & Ring $2 b$ & Group 1c & Group 2d \\
\hline 120 & 2 & -7.08 & 0 & 46 & 46 & 2 & 2 \\
\hline 121 & 2 & -6.14 & 3 & 1 & 1 & 48 & 47 \\
\hline 122 & 2 & -6.10 & 1 & 8 & 8 & 41 & 42 \\
\hline 123 & 2 & -0.656 & 12 & 48 & 47 & 1 & 1 \\
\hline 124 & 2 & 2.089 & 1 & 48 & 41 & 1 & 1 \\
\hline 125 & 0 & 5.02 & 0 & 55 & 39 & 2 & 1 \\
\hline 126 & 0 & 5.06 & 1 & 38 & 55 & 2 & 3 \\
\hline 127 & 0 & 5.69 & 0 & 47 & 45 & 3 & 3 \\
\hline 128 & 0 & 5.90 & 1 & 47 & 41 & 2 & 2 \\
\hline 129 & 0 & 6.99 & 1 & 44 & 43 & 5 & 5 \\
\hline $\mathrm{MO}$ & occ & $\mathrm{F}(\mathrm{eV})$ & JV( $)$ & Bipy & ings & Carb & roups \\
\hline MO & occ & $\mathrm{E}(\mathrm{eV})$ & $\operatorname{IV}(\alpha)$ & Ring 1a & Ring $2 b$ & Group 1c & Group 2d \\
\hline 122 & 2 & -7.19 & 1 & 7 & 62 & 10 & 43 \\
\hline 123 & 2 & -7.15 & 1 & 7 & 25 & 23 & 14 \\
\hline 124 & 2 & -7.00 & 0 & 8 & 8 & 7 & 1 \\
\hline 125 & 2 & -6.31 & 1 & 8 & 2 & 84 & 3 \\
\hline 126 & 2 & -6.15 & 0 & 7 & 5 & 7 & 87 \\
\hline 127 & 0 & 4.68 & 2 & 3 & 93 & 1 & 0 \\
\hline 128 & 0 & 4.85 & 2 & 92 & 3 & 0 & 1 \\
\hline 129 & 0 & 5.43 & 3 & 25 & 59 & 11 & 9 \\
\hline 130 & 0 & 5.52 & 1 & 58 & 29 & 24 & 3 \\
\hline 131 & 0 & 5.86 & 1 & 6 & 92 & 2 & 0 \\
\hline
\end{tabular}




\begin{tabular}{|c|c|c|c|c|c|c|c|}
\hline \multirow{2}{*}{ MO } & \multirow{2}{*}{ occ } & \multirow{2}{*}{$\mathrm{E}(\mathrm{eV})$} & \multirow{2}{*}{$\operatorname{IV}(\boldsymbol{\beta})$} & \multicolumn{2}{|c|}{ Bipyridine rings } & \multicolumn{2}{|c|}{ Carboxylic groups } \\
\hline & & & & Ring 1a & Ring $2 b$ & Group 1c & Group $2 d$ \\
\hline 121 & 2 & -7.29 & 1 & 4 & 18 & 18 & 59 \\
\hline 122 & 2 & -7.18 & 1 & 17 & 5 & 60 & 16 \\
\hline 123 & 2 & -6.38 & 1 & 2 & 4 & 6 & 88 \\
\hline 124 & 2 & -6.23 & 0 & 5 & 1 & 88 & 7 \\
\hline 125 & 2 & -0.31 & 1 & 51 & 45 & 1 & 1 \\
\hline 126 & 0 & 2.18 & 1 & 46 & 51 & 1 & 1 \\
\hline 127 & 0 & 5.07 & 3 & 24 & 66 & 2 & 5 \\
\hline 128 & 0 & 5.31 & 0 & 67 & 25 & 5 & 2 \\
\hline 129 & 0 & 5.79 & 1 & 12 & 83 & 1 & 2 \\
\hline 130 & 0 & 5.95 & 1 & 84 & 12 & 3 & 1 \\
\hline
\end{tabular}

${ }^{1 a}$ Atoms N18, C24, C25, C26, C27, C32, C33, C34, C35, C38, C39 and N19 form ring 1. ${ }^{2 b}$ Atoms N6, C1, C2, C3, C5, C7, C9, C11, C14, C15, $\mathrm{C} 22$ and $\mathrm{N} 10$ form ring $2 .{ }^{1 \mathrm{c}} \mathrm{A}$ tomsO20, $\mathrm{C} 28$ and $\mathrm{O} 36$ form group $1 .{ }^{2 \mathrm{~d}} \mathrm{AtomsO} 17, \mathrm{C} 16$ and $\mathrm{O} 23$ form group 2.

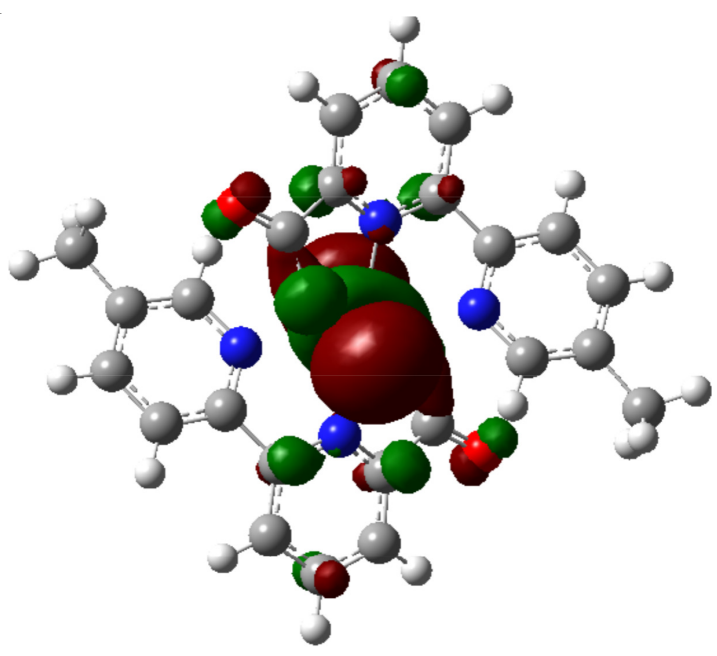

I-HOMO

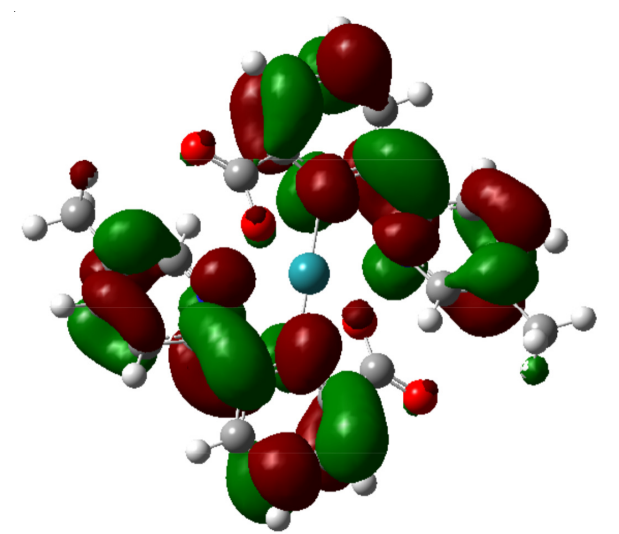

I-LUMO

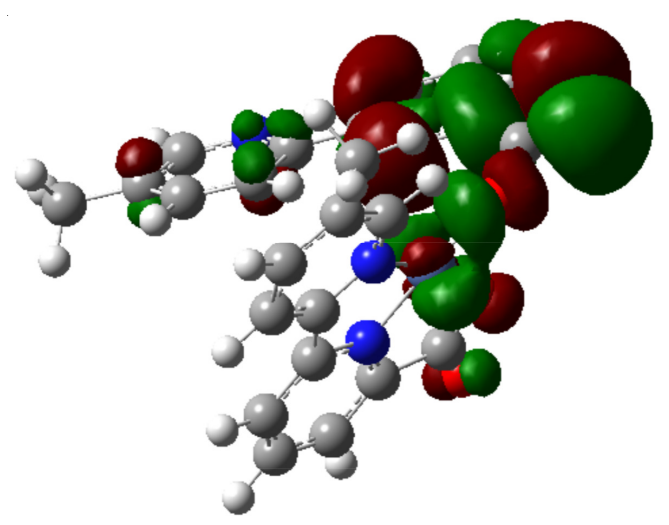

II-HOMO

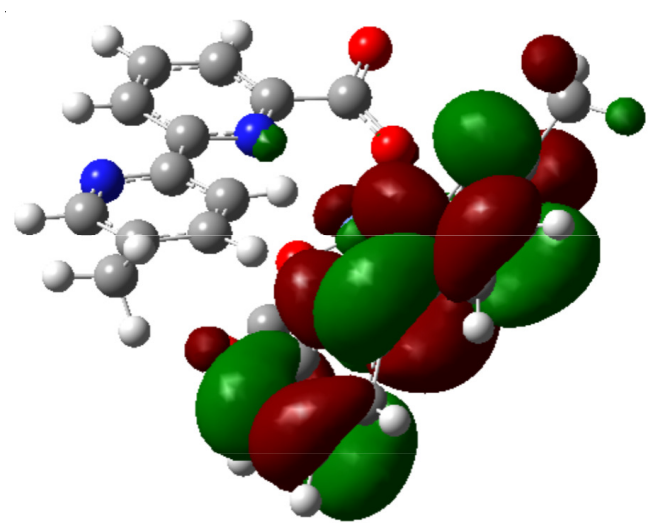

II-LUMO

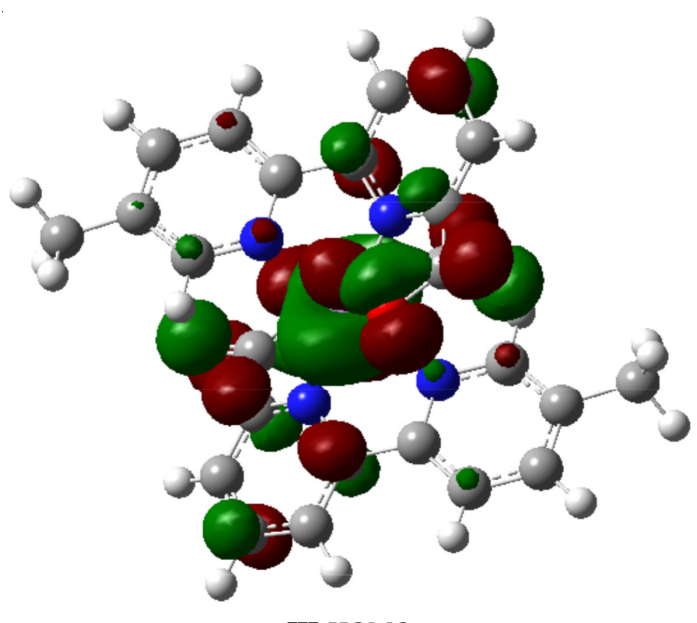

III-HOMO

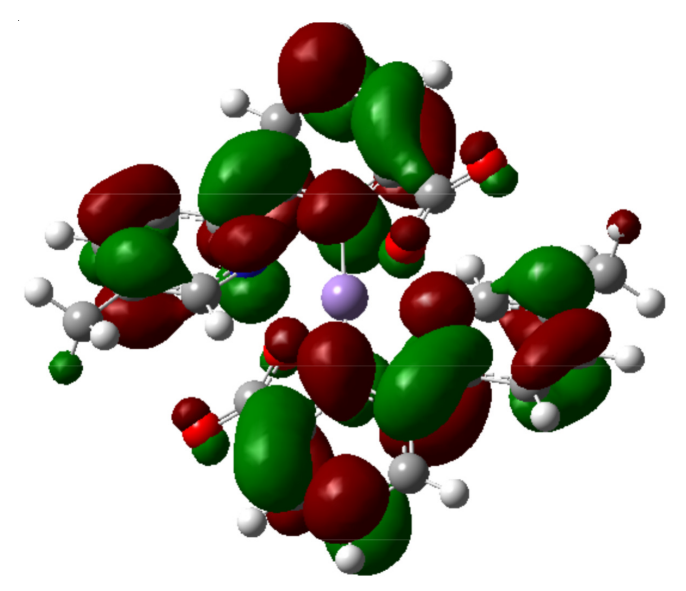

III-LUMO 


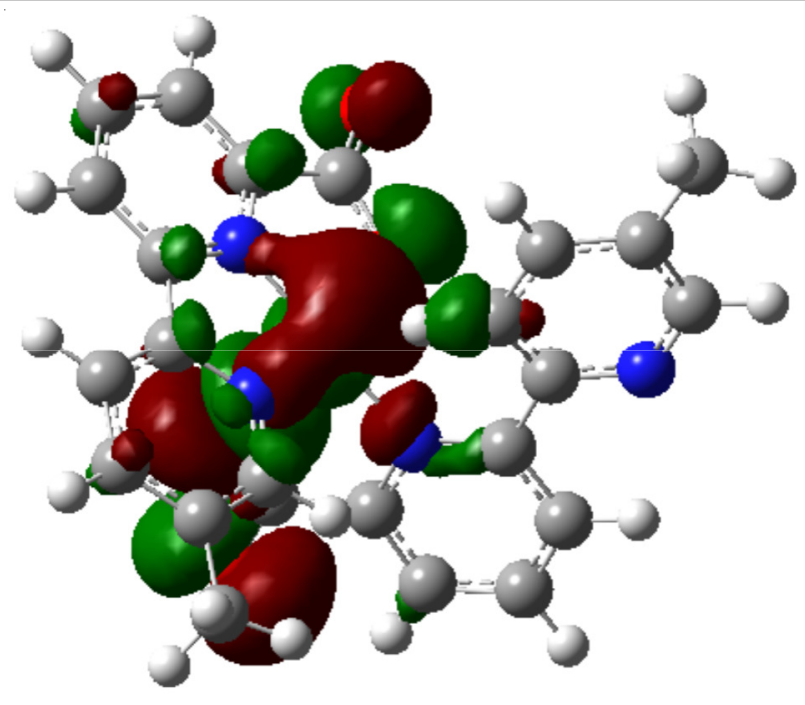

IV-HOMO

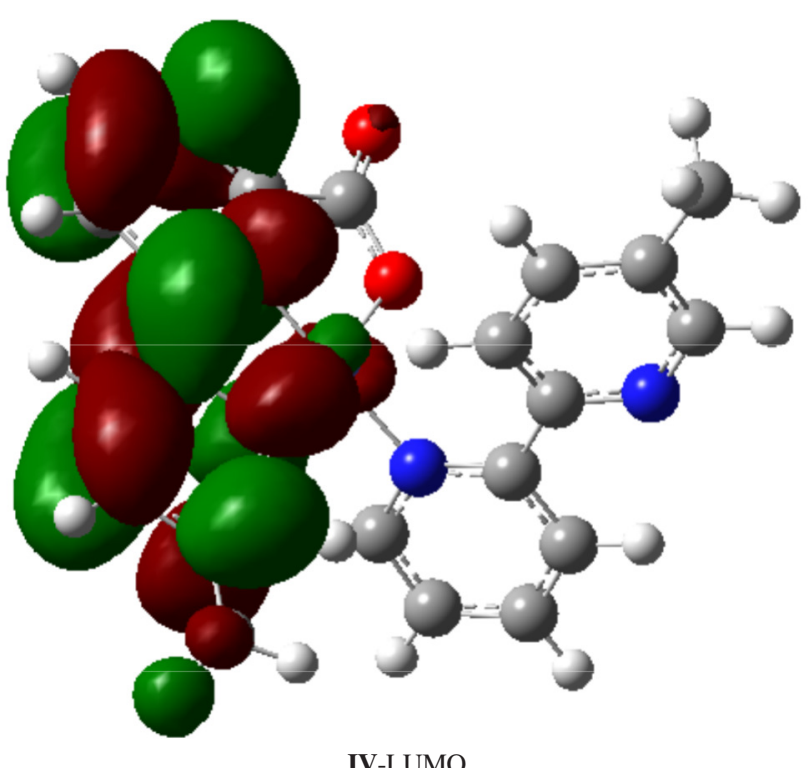

Fig. 3. Isodensity plots of the frontier orbitals of the complexes I-IV

are close to the reported results ${ }^{26}$ although the absolute values are larger than that reported.

The other complexes have not been reported, we use the same method to study the tendency of the electronic structure. For compound II Ni(II) $\mathrm{L}_{2}$, the pattern of occupied orbitals is qualitatively similar to that of the complex I. For the HOMO orbital, the largest orbital contributions arise from the metal atom $(72 \%)$ mixed with fewer characters of bipyridine rings (7-8 \%) and carboxylic groups (6-7 \%). But for the HOMO-1 and HOMO-2, the orbital contributions are mainly from the carboxylic groups (30-46\%), while for the HOMO-3 and HOMO-4, the orbital contributions are mainly from the bipyridine rings (27-37\%) and the carboxylic groups (10$19 \%$ ). The five lowest LUMOs of complex II is $\pi^{*}$ orbital's delocalized over the bipyridine ligands, over the range 29$90 \%$, with a little localization on the carboxylic groups, over the range $0-9 \%$. As this kind of sensitizers in photovoltaic solar cells anchor to $\mathrm{TiO}_{2}$ semiconductor surface via acidic carboxylic or phosphoric units, it is commonly considered that large contribution from the carboxylic or phosphoric groups to the $\pi^{*}$ LUMOs, which associate with the final states in MLCT transitions, would favour the electron injection to $\mathrm{TiO}_{2}$ conduction band quickly ${ }^{26,47}$.

For compound III Mn(II) $\mathrm{L}_{2}$ and compound IV Cu(II) $\mathrm{L}_{2}$, the patterns of occupied orbitals are qualitatively different from that of complex I. In these two complexes, there are two single electrons, which are an $\alpha$ electron and $\beta$ electron. In compound III, for the a electron, the HOMO of this complex is delocalized over on the carboxylic groups and a little on the bipyridine ligands, over the range 32-48 and 9-11\%, respectively, while for the $\beta$ electron, the HOMO of this complex is delocalized over on the bipyridine rings, the metal atom and a little on the carboxylic groups, in the range of $47-48 \%, 12 \%$ and $1 \%$, respectively. For the HOMO-n $(n=1-4)$, the electron cloud delocalized over on the bipyridine rings and the carboxylic groups and the maximum percentage composition are $48 \%$. The six lowest LUMOs are $\pi^{*}$ orbital's delocalized over on the bipyridine ligands, ranging from 36-55 \% and a little on the carboxylic groups, ranging from 1-7 \%. In compound IV, for the $\alpha$ electron, the HOMO is delocalized over on the carboxylic groups and a little on the bipyridine ligands, over the range 7-87 and 5-7 \%, respectively, while for the $\beta$ electron, the HOMO is delocalized over on the bipyridine ligands and a little on the carboxylic groups, over the range 45-51 and $1 \%$, respectively. For the other HOMO-n $(n=1-4)$, the electron cloud delocalized over on the carboxylic groups. The six lowest LUMOs of both complexes are $\pi^{*}$ orbital's delocalized over the bipyridine ligands, over the range 3-92 \% and 12-84 \% for $\alpha$ and $\beta$ electrons, respectively. In compound III, the electron transition forms are LLCT and MLCT, while in compound IV, which associate with the final states in LLCT transitions, $\mathrm{M}$ atoms only act as a bridge of LLCT transitions. The electron transition form of compound IV is different from those in compound I, II and III. In compound III, which associate with the final states in MLCT and LLCT transitions, the sensitizer would favour the electron injection to $\mathrm{TiO}_{2}$ conduction band quickly ${ }^{26,47}$. However, there exists such a little contribution from the carboxylic groups to the $\pi^{*}$ LUMOs in the complex. It is attributed to the two carboxylic groups coordinating to the central $\mathrm{Mn}$ atom via two oxygen atoms, instead of being free to make a possible direct anchoring to $\mathrm{TiO}_{2}$ surface just as that in the $\mathrm{N} 3$ and black dye ${ }^{48,49}$. So just as Falaras et al., showed, some reagent like $\mathrm{HCl}$ should be used to break $\mathrm{Ru}-\mathrm{O}$ bonds and make carboxylic groups to adsorb on the $\mathrm{TiO}_{2}$ surface ${ }^{26}$.

Optical absorption spectrum: TDDFT//B3P86/ LANL2DZ and TDDFT//B3P86/LANL2MB have been used to study the optical absorption spectra of organic metal compounds (Fig. 4). In order to inspect the method exactness, we selected the reported compound $\mathbf{I}^{26}$ as a benchmark for comparison. Electronic excitation energies (wavelengths $\lambda$ / $\mathrm{nm}$ ), oscillator strengths $\mathrm{f}$ and the nature of the respective excited states (principal CI-coefficients) calculated by the TDDFT method for all complexes were summarized in Table-3. Experimentally, the reported UV-visible maxima were found to be at 528 and $383 \mathrm{~nm}$ and a shoulder peak at $431 \mathrm{~nm}$ for the compound $\mathbf{I}\left(10^{-4} \mathrm{~mol} \mathrm{~L}^{-1}\right.$ solution in DMF). However, the corresponding DFT values, based on B3LYP/LANL2DZ and 


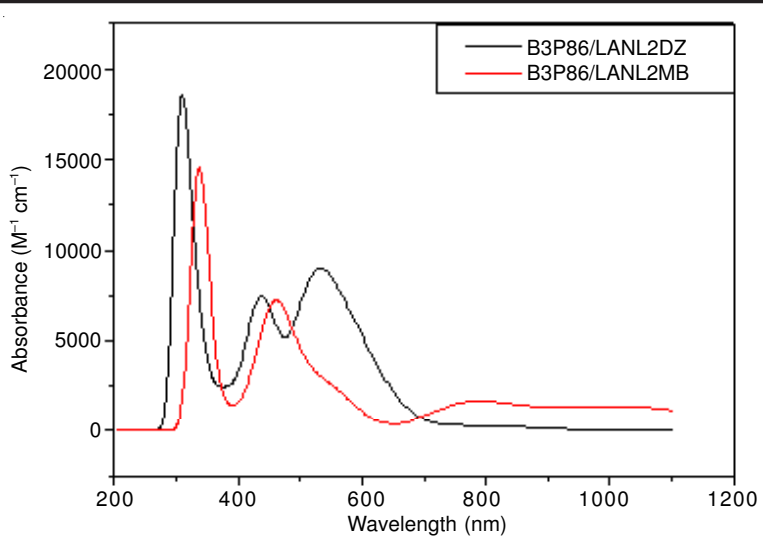

Calculated UV-visible spectra obtained for compounds I

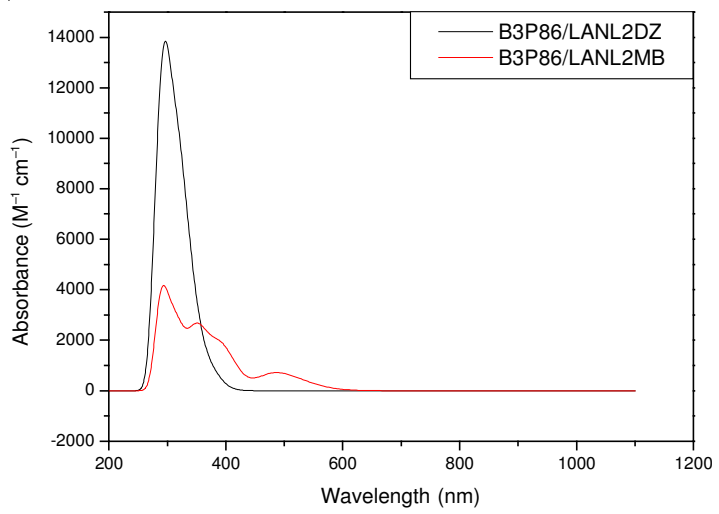

Calculated UV-visible spectra obtained for compounds II

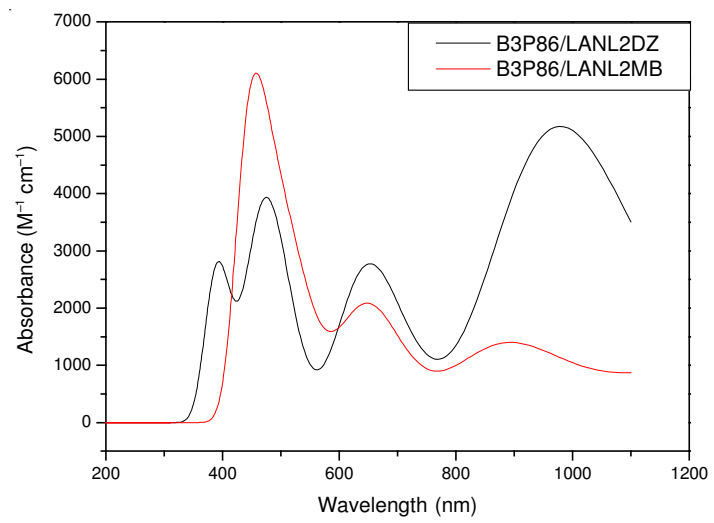

Calculated UV-visible spectra obtained for compounds III

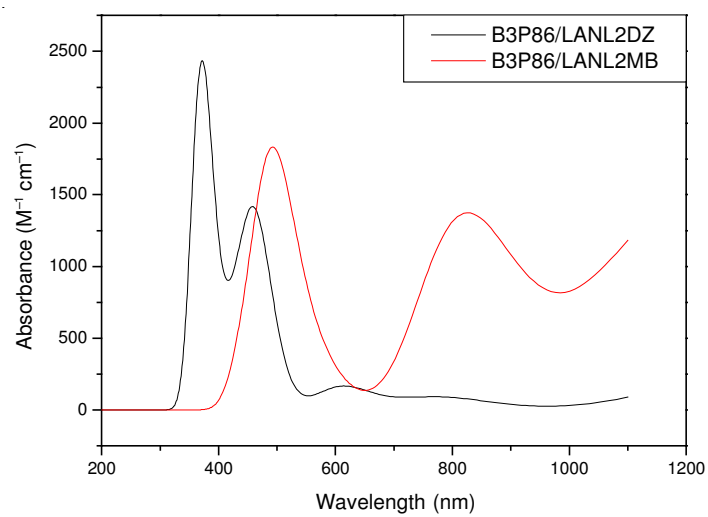

Calculated UV-visible spectra obtained for compounds IV

Fig. 4. Calculated UV-visible spectra obtained for compounds I-IV by the B3P86/LANL2DZ and B3P86/LANL2MB method
B3LYP/LANL2MB, are 203/244 and 341/460 nm, while the corresponding B3P86/LANL2DZ and B3P86/LANL2MB values are $307 / 432 / 530$ and $334 / 456 \mathrm{~nm}$, respectively. There are larger errors in the results using the B3LYP method compared with the experimental data. The values at 307, 432 and $530 \mathrm{~nm}$ from the B3P86/LANL2DZ method are in agreement with the reported absorption spectra ${ }^{26}$. This means that the outcomes based on the Becke-style 3-parameter density function theory using the Perdew86 correlation functional are more accurate than the outcomes based on the Becke-style 3-parameter density function theory using the Lee-Yang-Parr correlation functional. It is obvious that positions of the two band maximums in the observed spectrum are well reproduced in the simulated spectrum. However, the minimal wavelength and the relative intensity are not consistent well with the experimental data. Contrary to the experimental information, the simulated near-UV band is much higher than the visible one. The molar absorptive of the band maximum in visible region is slightly underestimated, while the one in the nearUV region is significantly overestimated. Similar results in simulation of N3-type dye also exist $\mathrm{t}^{50-52}$.

In compound II there is only one band maximum in the observed spectrum, while the corresponding DFT value, based on B3P86/LANL2DZ is at $321 \mathrm{~nm}$. The transition form is mainly on the $\mathrm{HOMO}_{-2}-\mathrm{LUMO}_{+1}(14 \%), \mathrm{HOMO}_{-3}-\mathrm{LUMO}$ (19\%), HOMO-5-LUMO (18\%), HOMO-6-LUMO (28\%). The all absorption peaks are in ultraviolet region. This means that the compound is not suitable as the dye-sensitized solar cell sensitizer.

In compound III, there are four band maxima in the observed spectrum, while the corresponding DFT values, based on B3P86/LANL2DZ and B3P86/LANL2MB, are 461/498/ 646/979 and 446/645/892 nm (Fig. 4), respectively. There are two single electrons in compound III, which are an $\alpha$ electron and $\beta$ electron. The maximum absorption is in HOMO-LUMO of $\beta$-electron transition at $979 \mathrm{~nm}$. At the $646 \mathrm{~nm}$, the transition form is $\mathrm{HOMO}-\mathrm{LUMO}_{+2}$ of $\beta$ electron transition. At the 498 $\mathrm{nm}$, the contribution of the transition forms are complex, the main contribution are $\alpha$ electron transition in HOMO-LUMO, HOMO $_{-1}$-LUMO and a few of an $\beta$ electron transition in HOMO-LUMO +5 . At the $461 \mathrm{~nm}$, the contribution of the transition forms are more complex, the main contribution are a electron transition in $\mathrm{HOMO}_{-1}$-LUMO, $\mathrm{HOMO}_{-2}$-LUMO, $\mathrm{HOMO}_{-4}-\mathrm{LUMO}_{+1}, \mathrm{HOMO}_{-6}-\mathrm{LUMO}_{+3}, \mathrm{HOMO}_{-8}-\mathrm{LUMO}_{+1}$ and a few of an $\beta$ electron transition in $\mathrm{HOMO}_{-4}-\mathrm{LUMO}_{+1}, \mathrm{HOMO}_{-5-}$ LUMO, $\mathrm{HOMO}_{-7}-\mathrm{LUMO}_{\mathrm{HOMO}} \mathrm{HO}_{-8} \mathrm{LUMO}_{+1}$. From the above analysis of the contribution to the HOMOs and LUMOs (Table2 ), the transition form is attributed to the LLCT with a few MLCT. The absorption peaks are all in visible region, the $\lambda_{\max }$ band in complex III has a large red-shift when compared to the standard compound $\mathbf{I}$. This means that the panchromatic response of compound III renders it as a suitable sensitizer for solar energy conversion applications.

In compound $\mathbf{I V}$, there are three band maxima in the observed spectrum, while the corresponding DFT values, based on B3P86/LANL2DZ and B3P86/LANL2MB, are 379/462/ 617 and 492/822/824 nm, (Fig. 4), respectively. There are also two single electrons in this compound, which are $\alpha$ and $\beta$ electrons. There are many transitions with small oscillator 
TABLE-3

ELECTRONIC EXCITATION ENERGIES (WAVELENGTHS $\lambda / \mathrm{nm}$ ), OSCILLATOR STRENGTHS $\mathrm{f}$ AND NATURE OF THE RESPECTIVE EXCITED STATE (PRINCIPAL CI-COEFFICIENTS) CALCULATED BY THE TDDFT METHOD FOR ALL COMPOUNDS

\begin{tabular}{|c|c|c|c|c|c|c|c|c|}
\hline \multirow{2}{*}{ Comp. } & \multicolumn{4}{|c|}{ B3LYP/LANL2DZ } & \multicolumn{4}{|c|}{ B3LYP/LANL2MB } \\
\hline & $\lambda(\mathrm{nm})$ & $\mathrm{f}$ & CI & Main configurations & $\lambda(\mathrm{nm})$ & $\mathrm{f}$ & CI & Main configurations \\
\hline \multirow{5}{*}{ I } & 246 & 0.4976 & 0.4770 & HOMO-LUMO & 1036.99 & 0.0176 & 0.6695 & HOMO-LUMO \\
\hline & 231 & 0.0669 & 0.2860 & $\mathrm{HOMO}_{-7}-\mathrm{LUMO}_{+2}$ & 779.81 & 0.0219 & 0.6753 & $\mathrm{HOMO}_{-1}$-LUMO \\
\hline & 221 & 0.0288 & 0.3099 & $\mathrm{HOMO}_{-1}-\mathrm{LUMO}_{+2}$ & 555.76 & 0.0249 & 0.6603 & HOMO-LUMO $_{+2}$ \\
\hline & 212 & 0.0567 & 0.3709 & $\mathrm{HOMO}_{-1}-\mathrm{LUMO}_{+5}$ & 473.83 & 0.0235 & 0.5115 & $\mathrm{HOMO}_{-1}-\mathrm{LUMO}_{+2}$ \\
\hline & 204 & 0.4429 & 0.3521 & $\mathrm{HOMO}_{-2}$-LUMO & 460.03 & 0.0507 & 0.5524 & $\mathrm{HOMO}_{-6}$-LUMO \\
\hline \multirow{9}{*}{ II } & 391 & 0.0035 & 0.59285 & HOMO-LUMO & 513 & 0.0047 & 0.8552 & HOMO-LUMO \\
\hline & 236 & 0.0958 & 0.31101 & $\mathrm{HOMO}_{-11}$-LUMO & 476 & 0.0069 & 0.6406 & $\mathrm{HOMO}_{-1}$-LUMO \\
\hline & 233 & 0.6202 & 0.31962 & $\mathrm{HOMO}_{-1}-\mathrm{LUMO}$ & 385 & 0.0166 & 0.4235 & $\mathrm{HOMO}_{-1}-\mathrm{LUMO}_{+3}$ \\
\hline & 220 & 0.1522 & 0.23424 & $\mathrm{HOMO}_{-\mathrm{LUMO}_{+2}}$ & 355 & 0.0187 & 0.3535 & $\mathrm{HOMO}_{-4}-\mathrm{LUMO}_{+1}$ \\
\hline & 219 & 0.0637 & 0.25196 & $\mathrm{HOMO}_{-7}-\mathrm{LUMO}_{+6}$ & 326 & 0.0209 & 0.4973 & $\mathrm{HOMO}_{-\mathrm{LUMO}_{+5}}$ \\
\hline & 218 & 0.0014 & 0.26800 & $\mathrm{HOMO}_{-1}-\mathrm{LUMO}_{+2}$ & 310 & 0.0191 & 0.3678 & $\mathrm{HOMO}^{-\mathrm{LUMO}_{+5}}$ \\
\hline & 210 & 0.0013 & 0.38931 & $\mathrm{HOMO}_{-1}-\mathrm{LUMO}_{+6}$ & 298 & 0.0191 & 0.4037 & $\mathrm{HOMO}_{-1}-\mathrm{LUMO}_{+5}$ \\
\hline & 210 & 0.0271 & 0.38155 & $\mathrm{HOMO}^{-L U M O}{ }_{+6}$ & 296 & 0.0077 & 0.4653 & $\mathrm{HOMO}_{-1}-\mathrm{LUMO}_{+5}$ \\
\hline & 200 & 0.0079 & 0.27696 & $\mathrm{HOMO}_{-5}-\mathrm{LUMO}_{+2}$ & 284 & 0.0141 & 0.5264 & $\mathrm{HOMO}_{-6}$-LUMO \\
\hline \multirow{7}{*}{ III } & 882 & 0.0639 & 0.9640 & HOMO-LUMO & 1291 & 0.0165 & 0.9467 & HOMO-LUMO \\
\hline & 605 & 0.0254 & 0.9779 & $\mathrm{HOMO}_{-1}$-LUMO & 881 & 0.0184 & 0.9301 & HOMO-LUMO $_{(\alpha)}$ \\
\hline & 504 & 0.0349 & 0.9611 & $\mathrm{HOMO}^{-\mathrm{LUMO}_{+2}}$ & 633 & 0.0152 & 0.9112 & $\mathrm{HOMO}_{-1}$-LUMO \\
\hline & 485 & 0.0093 & 0.9865 & HOMO-LUMO $_{(\alpha)}$ & 541 & 0.0129 & 0.6408 & HOMO-LUMO $_{+2(\alpha)}$ \\
\hline & 465 & 0.0206 & 0.8831 & $\mathrm{HOMO}_{-1}-\mathrm{LUMO}_{+2}$ & 506 & 0.0167 & 0.5941 & $\mathrm{H}_{-2}-\mathrm{LUMO}_{+2(\alpha)}$ \\
\hline & 412 & 0.0055 & 0.4306 & $\mathrm{HOMO}_{-1}-\mathrm{LUMO}_{(\alpha)}$ & 468 & 0.0139 & 0.4377 & $\mathrm{H}_{-1}-\mathrm{LUMO}_{+2(\alpha)}$ \\
\hline & 403 & 0.0151 & 0.7726 & HOMO-LUMO $_{+5(\alpha)}$ & 451 & 0.0364 & 0.4988 & HOMO-LUMO $_{+5(\alpha)}$ \\
\hline \multirow{7}{*}{ IV } & 1381 & 0.0039 & 0.7080 & HOMO-LUMO & 1010 & 0.0247 & 0.5388 & HOMO-LUMO \\
\hline & 477 & 0.0052 & 0.5979 & $\mathrm{HOMO}_{-2}-\mathrm{LUMO}$ & 705 & 0.0093 & 0.9774 & HOMO-LUMO $_{+1}$ \\
\hline & 470 & 0.0047 & 0.8244 & $\mathrm{HOMO}_{-1}$-LUMO & 616 & 0.0046 & 0.9760 & $\mathrm{HOMO}^{-\mathrm{LUMO}_{+2}}$ \\
\hline & 456 & 0.0049 & 0.8767 & $\mathrm{HOMO}-L U M O_{+2}$ & 553 & 0.0065 & 0.4669 & $\mathrm{HOMO}_{-1}-\mathrm{LUMO}_{+1}$ \\
\hline & 370 & 0.0057 & 0.4662 & $\mathrm{HOMO}_{-3}-\mathrm{LUMO}_{(\alpha)}$ & 542 & 0.0069 & 0.5018 & $\mathrm{HOMO}_{-1}-\mathrm{LUMO}_{(\infty)}$ \\
\hline & - & - & - & - & 526 & 0.0047 & 0.5646 & HOMO-LUMO $_{(\alpha)}$ \\
\hline & - & - & - & - & 510 & 0.0088 & 0.5272 & HOMO-LUMO $_{+3}$ \\
\hline \multirow{2}{*}{ Comp. } & \multicolumn{4}{|c|}{ B3P86/ LANL2DZ } & \multicolumn{4}{|c|}{ B3P86/ LANL2MB } \\
\hline & $\lambda(\mathrm{nm})$ & $\mathrm{f}$ & $\mathrm{CI}$ & Main configurations & $\lambda(\mathrm{nm})$ & $\mathrm{f}$ & $\mathrm{CI}$ & Main configurations \\
\hline \multirow{8}{*}{ I } & 594 & 0.0528 & 0.5966 & $\mathrm{HOMO}_{-1}$-LUMO & 781 & 0.0221 & 0.6736 & $\mathrm{HOMO}_{-1}$-LUMO \\
\hline & 522 & 0.1000 & 0.5466 & $\mathrm{HOMO}_{-\mathrm{LUMO}_{+2}}$ & 552 & 0.0256 & 0.6568 & $\mathrm{HOMO}^{-\mathrm{LUMO}_{+2}}$ \\
\hline & 442 & 0.0588 & 0.6166 & $\mathrm{HOMO}_{-1}$-LUMO & 471 & 0.0226 & 0.4912 & $\mathrm{HOMO}_{-1}-\mathrm{LUMO}_{+2}$ \\
\hline & 432 & 0.0392 & 0.6354 & $\mathrm{HOMO}_{-\mathrm{LUMO}_{+4}}$ & 455 & 0.0566 & 0.5671 & $\mathrm{HOMO}_{-7}$-LUMO \\
\hline & 328 & 0.0611 & 0.5857 & $\mathrm{HOMO}_{-6}-$ LUMO & 341 & 0.0156 & 0.5589 & $\mathrm{HOMO}_{-3}-\mathrm{LUMO}_{+3}$ \\
\hline & 319 & 0.0357 & 0.6455 & $\mathrm{HOMO}^{-\mathrm{LUMO}_{+6}}$ & 337 & 0.1487 & 0.4646 & $\mathrm{HOMO}_{-7}$-LUMO \\
\hline & 311 & 0.0224 & 0.6372 & $\mathrm{HOMO}_{-5}-\mathrm{LUMO}_{+1}$ & 333 & 0.0135 & 0.5261 & $\mathrm{HOMO}_{-3}-\mathrm{LUMO}_{+5}$ \\
\hline & 305 & 0.1965 & 0.5621 & $\mathrm{HOMO}_{-9}$-LUMO & 331 & 0.0213 & 0.4970 & $\mathrm{HOMO}_{-6}-\mathrm{LUMO}_{+2}$ \\
\hline \multirow{9}{*}{ II } & 344 & 0.0290 & 0.4566 & $\mathrm{HOMO}_{-3}-\mathrm{LUMO}$ & 478 & 0.0081 & 0.6448 & $\mathrm{HOMO}_{-1}$-LUMO \\
\hline & 333 & 0.0209 & 0.4303 & $\mathrm{HOMO}_{-5}$-LUMO & 401 & 0.0070 & 0.4557 & $\mathrm{HOMO}_{-3}-\mathrm{LUMO}_{+1}$ \\
\hline & 321 & 0.0474 & 0.3510 & $\mathrm{HOMO}_{-6}-\mathrm{LUMO}$ & 386 & 0.0130 & 0.4059 & $\mathrm{HOMO}_{-1}-\mathrm{LUMO}_{+3}$ \\
\hline & 316 & 0.0380 & 0.5290 & $\mathrm{HOMO}_{-2}-\mathrm{LUMO}_{+1}$ & 350 & 0.0165 & 0.5291 & $\mathrm{HOMO}_{-3}-\mathrm{LUMO}_{+2}$ \\
\hline & 300 & 0.0410 & 0.4940 & $\mathrm{HOMO}_{-8}-\mathrm{LUMO}$ & 347 & 0.0071 & 0.4013 & $\mathrm{HOMO}_{-4}-\mathrm{LUMO}_{+1}^{+2}$ \\
\hline & 296 & 0.0332 & 0.5768 & $\mathrm{HOMO}_{-4}^{-}-\mathrm{LUMO}_{+2}$ & 322 & 0.0165 & 0.6032 & $\mathrm{HOMO}^{-L_{U M O}+5}$ \\
\hline & 292 & 0.0379 & 0.4922 & $\mathrm{HOMO}_{-7}-\mathrm{LUMO}_{+1}$ & 307 & 0.0184 & 0.4207 & $\mathrm{HOMO}_{-4}-\mathrm{LUMO}_{+4}$ \\
\hline & 290 & 0.0387 & 0.4127 & $\mathrm{HOMO}_{-3}-\mathrm{LUMO}_{+3}$ & 291 & 0.0356 & 0.3576 & $\mathrm{HOMO}_{-4}-\mathrm{LUMO}_{+2}$ \\
\hline & 279 & 0.0501 & 0.3498 & $\mathrm{HOMO}_{-3}-\mathrm{LUMO}_{+3}$ & 284 & 0.0145 & 0.2442 & $\mathrm{HOMO}_{-2}-\mathrm{LUMO}_{+6}$ \\
\hline \multirow{7}{*}{ III } & 979 & 0.0714 & 0.9529 & HOMO-LUMO & 1327 & 0.0153 & 0.9439 & HOMO-LUMO \\
\hline & 691 & 0.0074 & 0.9910 & $\mathrm{HOMO}_{-1}$-LUMO & 892 & 0.0189 & 0.9219 & HOMO-LUMO $_{(\alpha)}$ \\
\hline & 646 & 0.0326 & 0.9813 & $\mathrm{HOMO}_{-\mathrm{LUMO}_{+2}}$ & 645 & 0.0202 & 0.8692 & $\mathrm{HOMO}_{-1}$-LUMO \\
\hline & 498 & 0.0206 & 0.9174 & HOMO-LUMO ${ }_{(\alpha)}$ & 537 & 0.0152 & 0.6276 & $\mathrm{HOMO}^{-\mathrm{LUMO}_{+2(\alpha)}}$ \\
\hline & 476 & 0.0053 & 0.6591 & $\mathrm{HOMO}_{-1}-\mathrm{LUMO}_{+2}$ & 506 & 0.0180 & 0.5539 & $\mathrm{H}_{-2}-\mathrm{LUMO}_{+2(\alpha)}$ \\
\hline & 461 & 0.0329 & 0.8265 & $\mathrm{HOMO}_{-1}-\mathrm{LUMO}_{(\alpha)}$ & 468 & 0.0173 & 0.4352 & $\mathrm{H}_{-1}-\mathrm{LUMO}_{+2(\alpha)}$ \\
\hline & - & - & - & - & 446 & 0.0322 & 0.6825 & HOMO-LUMO $_{+5(\alpha)}$ \\
\hline \multirow{5}{*}{ IV } & 1390 & 0.0036 & 0.7277 & HOMO-LUMO & 1216 & 0.0171 & 0.8535 & $\mathrm{HOMO}_{-2}$-LUMO \\
\hline & 464 & 0.0036 & 0.8417 & $\mathrm{HOMO}_{-4}$-LUMO & 824 & 0.0135 & 0.9757 & HOMO-LUMO $_{+1}$ \\
\hline & 462 & 0.0072 & 0.5998 & $\mathrm{HOMO}_{-2}$-LUMO & 822 & 0.0053 & 0.9807 & HOMO-LUMO $_{+2}$ \\
\hline & 417 & 0.0028 & 0.6275 & HOMO-LUMO $_{(\alpha)}$ & 472 & 0.0034 & 0.9792 & $\mathrm{HOMO}_{-\mathrm{LUMO}_{+6}}$ \\
\hline & 379 & 0.0041 & 0.3089 & $\mathrm{HOMO}_{-2}-\mathrm{L}_{+1(\alpha)}$ & 435 & 0.0023 & 0.6292 & $\mathrm{HOMO}_{-1}-\mathrm{L}_{+2(\alpha)}$ \\
\hline
\end{tabular}


strength obtained in this compound. At $617 \mathrm{~nm}$, the transition forms are $\mathrm{HOMO}_{2}-\mathrm{LUMO}(10 \%), \mathrm{HOMO}_{-8}-\mathrm{LUMO}(19 \%)$ and HOMO $_{-10^{-}}$LUMO (13\%) of $\beta$ electron transition. At the $462 \mathrm{~nm}$, the transition form is HOMO-LUMO ${ }_{+2}(17 \%)$, HOMO-LUMO (19\%), HOMO ${ }_{2}-$ LUMO (38 \%) and HOMO-4LUMO (24\%) of $\beta$ electron transition and HOMO-LUMO ( $1 \%$ ) of $\alpha$ electron transition. At the $379 \mathrm{~nm}$, the transition form is $\mathrm{HOMO}_{-1}-\mathrm{LUMO}_{+2}(7 \%), \mathrm{HOMO}_{-2}-\mathrm{LUMO}_{+1}(10 \%)$ and $\mathrm{HOMO}_{-3}-\mathrm{LUMO}_{+2}(23 \%)$, of $\beta$ electron transition and $\mathrm{HOMO}_{-1}-\mathrm{LUMO}_{+1}(4 \%), \mathrm{HOMO}_{-2}-\mathrm{LUMO}_{+1}(11 \%)$ and $\mathrm{HOMO}_{-3}-\mathrm{LUMO}_{+1}(4 \%)$ of $\alpha$ electron transition. From the above analysis of the contribution to the HOMOs and LUMOs (Table-2), more molecular orbitals contribute to those transitions of complex and the transition form is attributed to the LLCT. The absorption peaks are all in visible region and the $\lambda_{\max }$ band in complex IV has a large red-shift when compared to the standard compound $\mathbf{I}$. This means that the compound IV is also a suitable replacement as the dye-sensitized solar cell sensitizer.

\section{Conclusion}

In this paper, DFT methods have been used to study some organic-metal compounds. The geometry, electronic structure and optical absorption spectra of these organic-metal compounds have been investigated by means of combined DFT/TD-DFT calculations. Frontier orbital analysis shows different contributions of the HOMOs and LUMOs. In compounds I and II, the HOMOs are mainly on the metal atoms, the LUMOs are mainly on the bipyridine rings. This means that the electron transition is attributed to the MLCT. In compounds III and IV, the HOMOs are mainly on the bipyridine rings and carboxylic groups, the LUMOs are mainly on the bipyridine rings and a few on the carboxylic groups. There is only an oxygen atom of the carboxylic groups coordinating to the central metal atom. This made the other oxygen atom of the carboxylic groups to make a possible directed anchoring to $\mathrm{TiO}_{2}$ surface. The calculated absorption spectra (based on B3P86/LANL2DZ) are in excellent agreement with the experimental data of compound $\mathbf{I}$. The same method was used to predict the other compounds. The compounds III and IV show panchromatic response. The analysis of these compounds about the optical absorption spectra shows that the absorption peaks are all in visible region and the lmax bands in complexes III and IV have a large red-shift when compared to the standard compound I. Indicating that compound III and IV are suitable replacement as the dye-sensitized solar cell sensitizer. The normal transition metals to replace the noble metal will decrease cost of the dye-sensitized solar cells.

\section{ACKNOWLEDGEMENTS}

This work was supported by the Jiangsu Postdoctoral Foundation (Grant No. 1001010c) and the funds from Jiangsu Province Education Office (Serial No.: JH10-48).

\section{REFERENCES}

B. Oregan and M. Grätzel, Nature, 353, 737 (1991).

M. Grätzel, Nature, 414, 338 (2001).

A. Hagfeldt and M. Grätzel, Acc. Chem. Res., 33, 269 (2000).

M. Grätzel, J. Photochem. Photobiol. C, 4, 145 (2003).

S. Wang, Z.C. Yu, L. Han, C.L. Dai and J.Y. Song, Asian J. Chem., 24 214 (2012).
6. S. Altobello, R. Argazzi, S. Caramori, C. Contado, S.D. Fré, P. Rubino, C. Choné, G. Larramona and C.A. Bignozzi, J. Am. Chem. Soc., 127, 15342 (2005).

7. T. Yoshida, J. Zhang, D. Komatsu, S. Sawatani, H. Minoura, T. Pauporté, D. Lincot, T. Oekermann, D. Schlettwein, H. Tada, D. Wöhrle, K. Funabiki, M. Matsui, H. Miura and H. Yanagi, Adv. Funct. Mater., 19, 17 (2009).

8. F. Odobel, L.L. Pleux, Y. Pellegrin and E. Blart, Acc. Chem. Res., 43, 1063 (2010).

9. Y. Wang, Y. Liu, H. Yang, H. Wang, H. Shen and M. Li and J. Yan, Curr. Appl. Phys., 10, 119 (2010).

10. V.M. Guérin, C. Magne, T. Pauporté, T.L. Bahers and J. Rathousky, ACS Appl. Mater. Interf., 2, 3677 (2010).

11. S.E. Koops, B.C. O'Regan, P.R.F. Barnes and J.R. Durrant, J. Am. Chem. Soc., 131, 4808 (2009).

12. H.X. Wang, H. Li, B.F. Xue, Z.X. Wang, Q.B. Meng and L.Q. Chen, J. Am. Chem. Soc., 127, 6394 (2005).

13. B.F. Xue, Z.W. Fu, H. Li, X.Z. Liu, S.C. Cheng, J. Yao, D.M. Li, L.Q. Chen and Q.B. Meng, J. Am. Chem. Soc., 128, 8720 (2006).

14. M.K. Nazeeruddin, A. Kay, I. Rodicio, R. Humphry-Baker, E. Müller, P. Liska, N. Vlachopoulos and M. Grätzel, J. Am. Chem. Soc., 115, 6382 (1993).

15. M.K. Nazeeruddin, P. Pèchy, T. Renouard, S.M. Zakeeruddin, R. Humphry-Baker, P. Comte, P. Liska, L. Cevey, E. Costa, V. Shklover, L. Spiccia, G.B. Deacon, C.A. Bignozzi and M. Grätzel, J. Am. Chem. Soc., 123, 1613 (2001).

16. J.J. Lagref, M.K. Nazeeruddin and M. Grätzel, Synth. Met., 138, 333 (2003).

17. Y.N. Park, Y.M. Jung, S. Sarker, J.J. Lee, Y.H. Lee, K.T. Lee, J.J. Oh and S.W. Joo, Sol. Energy Mater. Sol. Cells, 94, 857 (2010).

18. J.M. Villegas, S.R. Stoyanov, W. Huang, L.L. Lockyear, J.H. Reibenspies and D.P. Rillema, Inorg. Chem., 43, 6383 (2004).

19. A. Mishra, M.K.R. Fischer and P. Bäuerle, Angew. Chem. Int. Ed., 48, 2474 (2009).

20. S. Altobello, R. Argazzi, S. Caramori, C. Contado, S.D. Fré, P. Rubino, C. Choné, G. Larramona and C.A. Bignozzi, J. Am. Chem. Soc., 127, 15342 (2005).

21. M.K. Nazeeruddin, F. De Angelis, S. Fantacci, A. Selloni, G. Viscardi, P. Liska, S. Ito, B. Takeru and M. Grätzel, J. Am. Chem. Soc., 127, 16835 (2005).

22. Y. Chiba, A. Islam, Y.Watanabe, R. Komiya, N. Koide and L. Han, J. Appl. Phys. (Japan), 45, 638 (2006).

23. M.K. Nazeeruddin, T. Bessho, L. Cevey, S. Ito, C. Klein, F. De Angelis, S. Fantacci, P. Comte, P. Liska, H. Imai and M. Grätzel, J. Photochem. Photobiol. A, 185, 331 (2007).

24. F. Gao, Y. Wang, J. Zhang, D. Shi, M. Wang, R. Humphry-Baker, P. Wang, S.M. Zakeeruddin and M. Grätzel, Chem. Commun., 2635 (2008).

25. N.O. Komatsuzaki, M. Yanagida, T. Funaki, K. Kasuga, K. Sayama and H. Sugihara, Sol. Energy Mater. Sol. Cells, 95, 310 (2011).

26. Y. Xu, W.K. Chen, M.J. Cao, Sh. H. Liu, J.Q. Li, A.I. Philippopoulos and P. Falaras, Chem. Phys., 330, 204 (2006).

27. C. Barolo, M.K. Nazeeruddin, S. Fantacci, D.D. Censo, P. Comte, P. Liska, G. Viscardi, P. Quagliotto, F. D. Angelis, S. Ito and M. Grätzel, Inorg. Chem., 45, 4642 (2006).

28. A.I. Philippopoulos, E. Chatzivasiloglou, A. Terzis, T.P. Raptopoulou, P. Tisnès, C. Picard and P. Falaras, Inorg. Chem. Commun., 8, 162 (2005).

29. S. Sagdinc and H. Pir, Spectrochim. Acta A, 73, 181 (2009).

30. P.S. Liyanage, R.M. de Sliva and K.M.N. de Sliva, J. Mol. Struct. (Theochem.), 639, 195 (2003).

31. F.D. Angelis, S. Fantacci, A. Selloni and M.K. Nazeeruddin, Chem. Phys. Lett., 415, 115 (2005).

32. A. Islam, F.A. Chowdhury, Y. Chiba, R. Komiya, N. Fuke, N. Ikeda, K. Nozaki and L.Y. Han, Chem. Mater., 18, 5178 (2006).

33. T. Bessho, E. Yoneda, J.H. Yum, M. Guglielmi, I. Tavernelli, H. Imai, U. Rothlisberger, M.K. Nazeeruddin and M. Grätzel, J. Am. Chem. Soc., 131, 5930 (2009).

34. F. Aiga and T. Tada, Sol. Energy Mater. Sol. Cells, 85, 437 (2005).

35. T.H. Dunning Jr. and P.J. Hay, In ed.: H.F. Schaefer III, In Modern Theoretical Chemistry, Plenum, New York, Vol. 3, No. 1 (1976).

36. P.J. Hay and W.R. Wadt, J. Chem. Phys., 82, 270 (1985).

37. W.R. Wadt and P.J. Hay, J. Chem. Phys., 82, 284 (1985).

38. P.J. Hay and W.R. Wadt, J. Chem. Phys., 82, 299 (1985).

39. W.J. Hehre, R.F. Stewart and J.A. Pople, J. Chem. Phys., 51, 2657 (1969). 
40. J.B. Collins, P.V.R. Schleyer, J.S. Binkley and J.A. Pople, J. Chem. Phys., 64, 5142 (1976).

41. HyperChem Pro. Release 6.03, Hypercube Inc., USA (2004).

42. S.M. Couchman, J.C. Jeffery and M.D. Ward, Polyhedron, 18, 2633 (1999).

43. P. Segla, D. Milkoš, P. Olejníková, B. Kalináková, D. Hudecová, M Palicová, J. Švorec, M. Valko, M. Melník and T. Glowiak, Inorg. Chim. Acta, 357, 4172 (2004).

44. M. Devereux, M. McCann, V. Leon, V. McKee and R.J. Ball, Polyhedron, 21, 1063 (2002).

45. E. Garribba, G. Micera and M. Zema, Inorg. Chim. Acta, 357, 2038 (2004).

46. M.J. Plater, M.R.S.J. Foreman, J.M.S. Skakle and R.A. Howie, Inorg. Chim. Acta, 332, 135 (2002).
47. S. Fantacci, F.D. Angelis and A. Selloni, J. Am. Chem. Soc., 125, 4381 (2003).

48. M.K. Nazeeruddin, A. Kay, I. Rodicio, R.H. Baker, E. Müller, P. Liska, N. Vlachopoulos and M. Grätzel, J. Am. Chem. Soc., 115, 6382 (1993).

49. M.K. Nazeeruddin, P. Pèchy, T. Renouard, S.M. Zakeeruddin, R.H. Baker, P. Comte, P. Liska, L. Cevey, E. Costa, V. Shklover, L. Spiccia, G.B. Deacon, C.A. Bignozzi and M. Grätzel, J. Am. Chem. Soc., 123, 1613 (2001).

50. J.E. Monat, J.H. Rodriguez and J.K. Mccusker, J. Phys. Chem. A, 106, 7399 (2002).

51. F.D. Angelis, S. Fantacci, A. Selloni and M.K. Nazeeruddin, Chem. Phys. Lett., 415, 115 (2005)

52. F.D. Angelis, S. Fantacci and A. Selloni, Chem. Phys. Lett., 389, 204 (2004). 